\title{
Quality of Life among Surgical Residents at King Abdulaziz Medical City in Jeddah, Saudi Arabia
}

\author{
Malik M. Almailabi ${ }^{1}$, Rakan S. Alajmi ${ }^{{ }^{*}}$, Atheel L. Balkhy ${ }^{1}$, Mohammed J. Khalifa ${ }^{1}$, Zaher A. Mikwar ${ }^{2}$, Muhammad A. Khan $^{3}$ \\ ${ }^{1}$ King Saud bin Abdulaziz University for Health Sciences, Jeddah, Saudi Arabia; ${ }^{2}$ Department of Surgery, King Abdulaziz \\ Medical City for the National Guard, Western Region, Jeddah, Saudi Arabia; ${ }^{3}$ College of Medicine, Department of Medical \\ Education, King Saud bin Abdulaziz University for Health Sciences, Jeddah, Saudi Arabia
}

Citation: Almailabi MM, Alajmi RS, Balkhy AL, Khalifa MJ, Mikwar ZA, Khan MA. Quality of Life among Surgica Residents at King Abdulaziz Medical City in Jedda Saudi Arabia. Open Access Maced J Med Sci. 2019 Dec https://doi.org/10.3889/oamjms.2019.854 Keywords: Quality of life; Stress; Burnout; Surgic residents

*Correspondence: Rakan S. Alajmi. King Saud bi Abdulaziz University for Health Sciences, Jeddah, Saud Arabia.E-mail. reeko7665@gmail.com

Received: 15-Jul-2019; Revised: 04-Aug-2019; Accepted: 05-Aug-2019; Online first: 13-Dec-2019

Copyright: @ 2019 Malik M. Almailabi, Rakan S. Alajm Atheel L. Balkhy, Mohammed J. Khalifa, Zaher A. Mikwa Muhammad A. Khan. This is an open-access article distributed under the terms of the Creative Commons Atribution-NonCommercial 4.0 International Liconse (CC

Funding: This research did not receive any financia support

Competing Interests: The authors have declared that no competing interests exis

\section{Abstract}

BACKGROUND: Surgical residency program is considered one of the toughest residency programs, which affects quality of life of the residents during training years. To date, no study has evaluated quality of life among residents, especially surgical residents here in Saudi Arabia.

AIM: The objective of this study is to evaluate quality of life among surgical residents

METHODS: The study is a cross-sectional study conducted during September 2018 in King Khalid Hospital at King Abdulaziz Medical City (KAMC) Jeddah, Saudi Arabia. The study utilized the Work-Related Quality of Life, WRQoL, scale which measures perceived quality of life covering six domains: General Well-Being (GWB), HomeWork Interface (HWI), Job and Career Satisfaction (JCS), Control at Work (CAW), Working Conditions (WCS) and Stress at Work (SAW), in addition to demographic questions, asking about (age, gender, marital status, resident level, specialty, BMI, smoking, number of days of exercise per week, hours of sleep per day, on-calls per month, clinics per week, operations per week).

RESULTS: Of the 99 surgical residents training at KAMC, 73 residents returned the survey with a response rate of $72.8 \%$. The mean age of the residents was $28+21$ years with the mean BMl of $25 \mathrm{~kg} / \mathrm{m} 2.54 .8 \%$ were married, and $42.5 \%$ were smokers. Half of the residents (50.7\%) working in King Abdulaziz Medical City have low work-related quality of life. In comparison between male and female residents' overall Quality of life, there was no significant difference between them $(p=0.363)$

CONCLUSIONS: Our main study finding is that half of the residents $(50.7 \%)$ working at KAMC has low work related quality of life, and there is no significant difference between male and female residents. Further studies are needed to determine the causes and improve the work-related quality of life among surgical residents.

\section{Introduction}

Long working hours, on call duties, academic lectures, and lack of autonomy make the period of surgical residency highly stressful [1]. Working hours and burnout among residents have gained much attention recently [2]. Attrition among surgical residents remains high, with rates of $14-23 \%$ [3]. In a recent study, which was published in 2018, it was shown that these high levels of stress are strongly associated with depression and burnout among residents [4]. Another study published from Japan in 2018, has supported that extremely long working hours were strongly associated with depression, which is one of the adverse effects of stress [5]. In another study that was conducted in Germany, analysis of psychosocial stress in the workplace among residents in the surgical field showed that this group suffers from more severe stress than other specialties [6].

A Swedish study reflected that high demand and job strains were as highly related to increased depression among men as among women [7]. Several studies have addressed stress and depression among residents, but the issue that has not been addressed properly is the relationship between gender, working environment, and development of stress or depression [5], [7], [8]. Another factor to discuss is how high workload can affect family and interpersonal relationships, which in result will affect the quality of life [9]. 
According to a published study in 2017 that measured burnout and stress among US surgery residents, higher stress is associated with increased risk of burnout in surgical residents, which will all ultimately affect the mental health and performance of the residents [10]. Burnout may erode professionalism, contribute to medical errors, lead to suicidal ideation and attrition, and can be a factor in substance abuse and relationship difficulties which will affect the quality of life of the residents [11].

Based on the literature, stress and depression are highly prevalent among surgical residents due to long working hours. To date, no local study has evaluated work-related quality of life of the residents, especially surgical residents here in Saudi Arabia. The objective of this study is to evaluate quality of life of the surgical residents and address the factors affecting their quality of life.

\section{Methods}

The study is a cross-sectional study conducted during September 2018 in King Khalid Hospital at King Abdulaziz Medical City Jeddah, Saudi Arabia. Before starting the study, the ethical approval was obtained from King Abdullah International Medical Research Center's (KAIMRC). The study utilized the first edition of the work related quality of life (WRQoL) scale developed by Simon Easton and Darren Van Laar [12]. This questionnaire is already tested for the validity and reliability the authors [12]. In addition to WRQoL questionnaire, demographic parameters like age, gender, marital status, residency level, specialty, BMI, smoking, number of days of exercise per week, hours of sleep per day, on-calls per month, clinics per week, and operations per week were obtained. Surgical residents from all specialties were given the questionnaire either by link or were given a hard copy; the consent was attached to both.

The questionnaire was distributed among all surgical residents, in our institute 103 residents, with a response rate of $72.8 \%$. Out of the those who answered 19 were general surgery residents, 2 Ophthalmology residents, 5 Plastic surgery residents, 3 Neurosurgery residents, 4 Urology residents, 12 Orthopedic surgery residents, 6 ENT head and neck surgery residents, 1 Pediatric surgery residents, 23 $\mathrm{OB} / \mathrm{GYN}$ residents.

\section{Data Analysis}

Data was entered and analyzed on SPSS version 20.0. For the analysis, frequency and percentage was computed for categorical variables like gender, marital status, and specialty of the residents. Mean and standard deviation was estimated for quantitative variables like age. Frequencies/percentages were shown in bar charts and for mean and standard deviation, tables were displayed. For inferential statistics chi-square test was used for comparing two categorical for gender and overall Quality of life. P-value $<0.05$ will be taken as significant.

\section{Result}

Of the 99 surgical residents training in King Khalid Hospital at King Abdulaziz Medical City, during September 2018, 73 returned the survey with a response rate of $72.8 \%$. Demographic features are depicted in Table 1.

Table 1: Demographic features

\begin{tabular}{lccc}
\hline Demographic features & \multicolumn{3}{l}{} \\
\hline Gender & $39(53.4 \%)$ male & The mean age & $28 \pm 2.1$ \\
& $34(46.6 \%)$ female & & $40(54.8 \%)$ married \\
The mean BMI & $25 \mathrm{~kg} / \mathrm{m}^{2}$ & Marital status & $33(55.2 \%)$ single \\
& $42(57.5 \%)$ non & Hours of sleep per & $4-6$ hours $(68.5 \%)$ \\
Smoking & smoker & night & $7-9$ hours $(31.5 \%)$ \\
& $31(42.5 \%)$ smoker & $1-3$ days $(67.1 \%)$ & \\
Days of exercise per & \multicolumn{4}{c}{$\begin{array}{l}\text { did not participate in any regular exercise }(8.2 \%) \\
\text { week }\end{array}$} \\
\hline
\end{tabular}

Regarding the specialties of the residents, refer to Table 2.

Table 2: The specialties of the residents

\begin{tabular}{lccc}
\hline Specialty & Number of residents & Specialty & Number of residents \\
\hline General surgery & $19(26 \%)$ & Ophthalmology & $2(2.7 \%)$ \\
Plastic surgery & $5(6.8 \%)$ & Neurosurgery & $3(4.1 \%)$ \\
Orthopedic & $10(13.7 \%)$ & Urology & $4(5.5 \%)$ \\
ENT & $6(8.2 \%)$ & Pediatric surgery & $1(1.4 \%)$ \\
Ob/Gyn & $23(31.5 \%)$ & & \\
\hline
\end{tabular}

Number of on-calls, clinics and operations are shown in Table 3.

Table 3: Number of on-calls, clinics and operations

\begin{tabular}{lc}
\hline Clinical duties & \\
\hline & $1-3(8.2 \%)$ \\
On-calls per month & $4-7(72.6 \%)$ \\
& $8-10(19.2 \%)$ \\
Clinics per week & $3(53.4 \%)$ \\
& $2(43.8 \%)$ \\
Operations per week & $1(2.7 \%)$ \\
& $1-3(47.9 \%)$ \\
& $4-6(37 \%)$ \\
& $7-9(9.6 \%)$ \\
\hline
\end{tabular}

The study showed that the majority of the residents $(76.7 \%)$ perceived them to have a low home-work interface. $34.2 \%, 41.1 \%$, and $24.7 \%$ displayed a low, average, and high job-career satisfaction. Nearly half $(46.6 \%)$ encountered high stress levels at work. Table 4 further describes the parameters studied. The quality of life for $50.7 \%$ of the residents was low, while 37\% reported an average quality of life, and $12.3 \%$ reported high quality of life. In comparison between male and female residents' overall Quality of life, there was no significant 
difference between them $(p=0.363)$.

Table 4: Six domains of WRQoL questionnaire

\begin{tabular}{lcc}
\hline Home-work interface & $\mathrm{n}$ & $\%$ \\
\hline Low & 56 & 76.7 \\
$\quad$ Average & 12 & 16.4 \\
$\quad$ High & 5 & 6.9 \\
Job-career satisfaction & & \\
$\quad$ Low & 25 & 34.2 \\
$\quad$ Average & 30 & 41.1 \\
$\quad$ High & 18 & 24.7 \\
Control at work & & \\
$\quad$ Low & 41 & 56.2 \\
$\quad$ Average & 20 & 27.4 \\
$\quad$ High & 12 & 16.4 \\
Working conditions & & \\
$\quad$ Low & 23 & 31.5 \\
Average & 16 & 21.9 \\
$\quad$ High & 34 & 46.6 \\
Stress at work & & \\
Low & 23 & 31.5 \\
Average & 16 & 21.9 \\
$\quad$ High & 34 & 46.6 \\
General well being $\quad$ Low & & \\
$\quad$ Average & 35 & 47.9 \\
$\quad$ High & 28 & 38.4 \\
Quality of life & 10 & 13.7 \\
$\quad$ Low & & \\
$\quad$ Average & 37 & 50.7 \\
$\quad$ High & 27 & 37 \\
\hline
\end{tabular}

\section{Home-Work Interface (HWI)}

The HWI factor addresses work-life balance and reflects the extent to which the employer is perceived to support employees' home life (12). $76.7 \%$ of our residents have low HWI, while $16.4 \%$ have average $\mathrm{HWI}$, and only $6.9 \%$ have high $\mathrm{HWI}$.

Table 5: Work-related quality of life scale

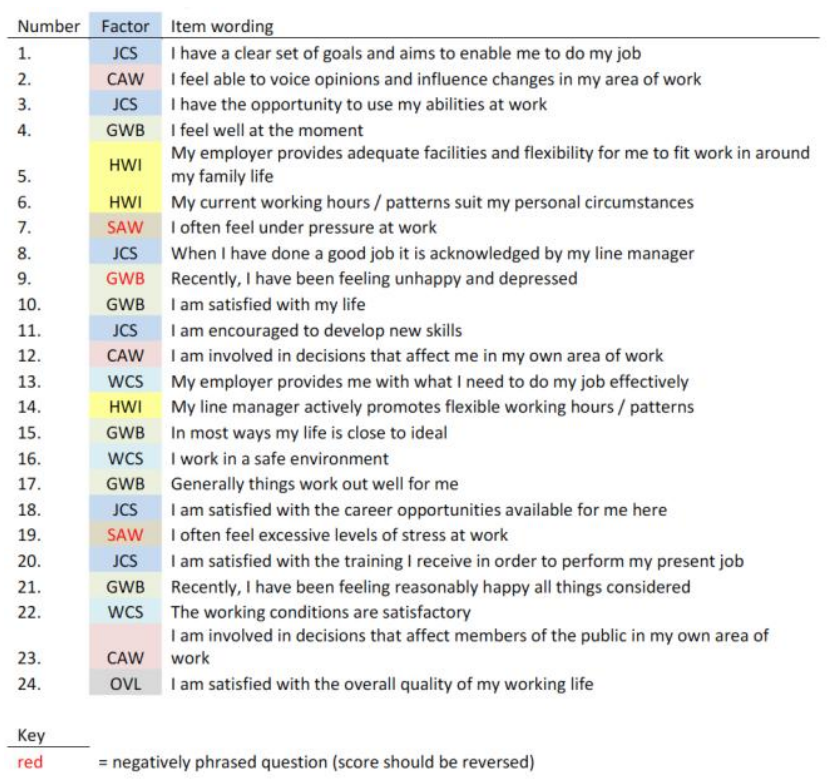

Work-related quality of life scale is a 23-item psychometric scale that measures perceived quality of life covering six domains: General Well-Being (GWB), Home-Work Interface (HWI), Job and Career Satisfaction (JCS), Control at Work (CAW), Working Conditions (WCS) and Stress at Work (SAW). This work-related quality of life scale is being used by individuals, consultants, and organizations as a great tool to assess the quality of working life among employees. Although the WRQoL scale has 23 items, an additional $24^{\text {th }}$ factor is added in the questionnaire to indicate the validily and reliabilty ol the WRQL scale. Table 5 illustrates tha neutral, agree, and strongly agree.

\section{Job and Career Satisfaction (JCS)}

The JCS represents the level to which the workplace provides a person with the best things in the working environment. For instance, sense of achievement, high self esteem and fulfilment of potential [12]. 34.2\% of our residents have low JCS, while most of them $41.1 \%$ have average JCS, and $24.7 \%$ have high JCS.

\section{Control at Work (CAW)}

The CAW factor reflects the level at which an employee feels they can exercise what they consider to be an appropriate level of control within their work environment. That perception of control might be linked to various aspects of work, including the opportunity to contribute to the process of decision making that affect them [12]. More than the half of our residents (56.2\%) had low CAW, while $27.4 \%$ had average CAW, and only $16.4 \%$ had high CAW.

\section{Working Conditions (WCS)}

The WCS assesses the extent to which the employee is satisfied with the fundamental resources, working conditions and security necessary to do their job effectively [12]. Most of our residents $46.6 \%$ had high WCS, $21.9 \%$ of them had average WCS, and $31.5 \%$ of the residents had low WCS.

\section{Stress at Work (SAW)}

The SAW factor is determined by the extent to which an individual perceives they have excessive pressures and feel stressed at work [12]. Most of our residents $46.6 \%$ had high SAW, while $21.9 \%$ of them had average SAW, and $31.5 \%$ of them had low SAW. This result reflects high stress at work among surgical residents in our hospital.

\section{The General Well-Being (GWB)}

The GWB factor assesses the extent to which an individual feels good or content with their life as a whole. General well-being is conceptualized as influencing and, being influenced by, work [12]. Most of our residents $47.9 \%$ had low general well-being, while $38.4 \%$ had average GWB, and only $13.7 \%$ had high GWB.

\section{Discussion}

The objective of this study is to evaluate the residents' quality of life. The final Work-Related Quality of Life (WRQoL) score is determined by taking the average of the 6 domains. After coding, our main study finding is that half of the residents $(50.7 \%)$ have low work-related quality of life. Out of the six domains, we observed that the following results are alarming, 
low Home-Work interface, low control at work, high stress at work, and low general well being.

Home-work interface subscale gives us an idea about how residents are supported in their family and home life [13]. When the residents are asked if they are given flexible working hours or patterns, most of the them $(76.6 \%)$ have low Home-work interface subscale. Lack of flexibility, long working hours and high job demands can interfere between home and work responsibilities, and these factors can explain why home-work interface subscale conducted in our sample size is low. Moreover, looking at the demographic data of the residents, half of them are married $(54.7 \%)$, and that might lower the subscale of Home-Work interface. Similarly, a study conducted in Germany proves that high job demand is one of the significant causes of high work-family conflict [9]. In contrast, there is a study that assessed Work-Related quality of life of US surgical residents, with the use of the same assessment tool used in our study, and revealed that only $22 \%$ of the residents have low home-work interface subscale [13]. This might be viewed as a huge gap between the US and Saudi surgical programs in terms of working hours, and the amount of support the residents receive towards their home and family life. Low Work-Life balance could negatively affect the residents' life inside and outside their working environment. In addition to low work-life balance adverse effects, physical and physiological issues like burnout and depression are highly prevalent [1], [5]. This high incidence of depression and burnout is also seen among oncology residents in Europe [14].

Knowing that work-place stress is a common job-related health problem, burnout and stress are more common in the medical field compared to other professions [11]. Stress can be manifested in any adverse reaction in response to excessive demands [12].

Unsurprisingly yet alarming, our results show that nearly half of the residents $(46.6 \%)$ scored high levels of stress. Pressures and stress can be great tools to drive the residents into a challenging environment, therefore, the patients will benefit from that challenging and driving working environment [13]. However, excessive stress levels can lead to burnout, which in turn will affect the residents' performance and mental health [10], [11]. A study found that limited resources, changing environment, and poor work-life balance are possible causes of this issue [15], [16]. To overcome this issue, a study concluded that mindfulness not only manage stress at work, but also it could be a preventive tool against burnout [10].

Not only stress and burnout, as mentioned previously, are higher in the medical field, but also general well being is worse than any other professions [3]. In fact, $47.9 \%$ of the surgical residents working in King Abdulaziz Medical City have low general well being subscale. Our results showed that low
Home-Work interface and high stress at work levels correlate with low general well being subscale. General well being subscale represents physical and psychological aspects of health. Home-Work interface and stress levels can explain the psychological part of General well being subscale. On the other hand, the residents' demographic data can give us an idea about the life habits and the physical part of General well being subscale. For example, and despite the fact that most of the residents exercise 1-3 or more per week, the mean BMl of the residents is $25 \mathrm{~kg} / \mathrm{m}^{2}$. Another important and notable finding is that $42.5 \%$ of the residents are smokers, and along with the BMI and high stress level, these findings can explain why general well being subscale is low in nearly half of the surgical residents. On the contrary, a study conducted in US concluded that sleep hours and activity level have no association with burnout and stress level [17)]. This should shift the focus to other factors other than activity level or sleep hours, workload for instance. In fact, workload is considered one of the most important causes when it comes to occupational stress [18]. For this reason, managers of the surgical residency program should work on reducing the workload in order to decrease burnout and stress levels [18].

A study revealed that female surgeons are more likely to experience burnout [19]. Moreover, the same study that conducted quality of life of US surgical residents concluded that female surgical residents have low quality of life in comparison to male surgical residents [12]. This is also mirrored in a South African study about female surgical residents who expressed concerns about maintaining a balance between work and life [20]. However, in our study, there was no significant difference between male and female surgical residents in overall Quality of life $(P=$ 0.363).

Strength and limitations of this study: - This is the first study evaluating the quality of life of surgical residents in Saudi Arabia; - This study is based on self-reported data, there might be a response bias involved; - Conducting the study in a single medical center cannot generalize our results.

Our main study finding is that half of the residents (50.7\%) working in King Abdulaziz Medical City has low work-related quality of life. Further studies are needed to determine the causes and improve the work-related quality of life among surgical residents.

\section{Acknowledgement}

The authors would like to thank all KAMC residents who volunteered to participate in this study. 


\section{Ethical Approval}

The study was approved by the Institutional Review Board (IRB) at King Abdullah International Medical Research Center (KAIMRC).

\section{References}

1. van Vendeloo S, Godderis L, Brand P, Verheyen K, Rowell S, Hoekstra H. Resident burnout: evaluating the role of the learning environment. BMC Medical Education. 2018; 18(1):20-28. https://doi.org/10.1186/s12909-018-1166-6 PMid:29587737 PMCid:PMC5872499

2. Golub JS, Weiss PS, Ramesh AK, Ossoff RH, Johns III MM. Burnout in residents of otolaryngology-head and neck surgery: a national inquiry into the health of residency training. Academic Medicine. 2007; 82(6):596-601.

https://doi.org/10.1097/ACM.0b013e3180556825 PMid:17525550

3. Elmore L, Jeffe D, Jin L, Awad M, Turnbull I. National Survey of Burnout among US General Surgery Residents. Journal of the American College of Surgeons. 2016; 223(3):440-51. https://doi.org/10.1016/i.jamcollsurg.2016.05.014 PMid:27238875 PMCid:PMC5476455

4. Simpkin A, Khan A, West D, Garcia B, Sectish T, Spector N et al. Stress From Uncertainty and Resilience Among Depressed and Burned Out Residents: A Cross-Sectional Study. Academic Pediatrics. 2018; 18(6):698-704.

https://doi.org/10.1016/j.acap.2018.03.002 PMid:29524616

5. Ogawa R, Seo E, Maeno T, Ito M, Sanuki M, Maeno T. The relationship between long working hours and depression among first-year residents in Japan. BMC Medical Education. 2018; 18(1):10-18. https://doi.org/10.1186/s12909-018-1171-9 PMid:29587738 PMCid:PMC5870810

6. Bernburg M, Vitzthum K, Groneberg D, Mache S. Physicians' occupational stress, depressive symptoms and work ability in relation to their working environment: a cross-sectional study of differences among medical residents with various specialties working in German hospitals. BMJ Open. 2016; 6(6):36-44. https://doi.org/10.1136/bmjopen-2016-011369 PMid:27311909 PMCid:PMC4916614

7. Theorell T, Hammarström A, Gustafsson P, Magnusson Hanson $\mathrm{L}$, Janlert $\mathrm{U}$. Job strain and depressive symptoms in men and women: A prospective study of the working population in Sweden. Journal of Epidemiology and Community Health. 2013; 68(1):7882. https://doi.org/10.1136/jech-2012-202294 PMid:24052515

8. Theorell T, Hammarström A, Aronsson G, Träskman Bendz L, Grape T, Hogstedt C. A systematic review including meta-analysis of work environment and depressive symptoms. BMC Public Health. 2015; 15(1):31-43. https://doi.org/10.1186/s12889-0151954-4 PMid:26232123 PMCid:PMC4522058
9. Mache S, Bernburg M, Vitzthum K, Groneberg D, Klapp B, Danzer G. Managing work-family conflict in the medical profession: working conditions and individual resources as related factors. BMJ Open. 2015; 5(4):10-19. https://doi.org/10.1136/bmjopen-2014006871 PMid:25941177 PMCid:PMC4420985

10. Lebares C, Guvva E, Ascher N, O'Sullivan P, Harris H, Epel E. Burnout and Stress Among US Surgery Residents: Psychological Distress and Resilience. Journal of the American College of Surgeons. 2018; 226(1):80-90. https://doi.org/10.1016/i.jamcollsurg.2017.10.010 PMid:29107117

11. Dyrbye L, West C, Satele D, Boone S, Tan L, Sloan J et al. Burnout Among U.S. Medical Students, Residents, and Early Career Physicians Relative to the General U.S. Population. Academic Medicine. 2014; 89(3):443-51.

https://doi.org/10.1097/ACM.0000000000000134 PMid:24448053

12. Easton S, Van Laar D. User manual of the Work- Related Quality of Life (WRQLL) scale: a measure of quality of working life. University of Portsmouth; 2012.

13. Bohrer T, Koller M, Schlitt HJ, Bauer H. Workload and quality of life of surgeons. Results and implications of a large-scale survey by the German Society of Surgery. Langenbeck's archives of surgery. 2011; 396(5):669-76. https://doi.org/10.1007/s00423-011-0791-x PMid:21509545

14. Mordant P, Deneuve S, Rivera C, Carrabin N, Mieog JS, Malyshev N, Van Der Vorst JR, Audisio RA. Quality of life of surgical oncology residents and fellows across Europe. Journal of surgical education. 2014; 71(2):222-8.

https://doi.org/10.1016/i.jsurg.2013.07.010 PMid:24602714

15. Low ZX, Yeo KA, Sharma VK, Leung GK, McIntyre RS, Guerrero A, et al. Prevalence of Burnout in Medical and Surgical Residents: A Meta-Analysis. MDPI. Multidisciplinary Digital Publishing Institute, 2019. https://doi.org/10.3390/ijerph16091479 PMid:31027333 PMCid:PMC6539366

16. Zubair MH, Hussain LR, Williams KN, Grannan KJ. WorkRelated Quality of Life of US General Surgery Residents: Is It Really so Bad?. Journal of surgical education. 2017; 74(6):e13846. https://doi.org/10.1016/i.jsurg.2017.09.018 PMid:28988955

17. Marek AP, Nygaard RM, Liang ET, Roetker NS, DeLaquil M, Gregorich S, Richardson CJ, Van Camp JM. The association between objectively-measured activity, sleep, call responsibilities, and burnout in a resident cohort. BMC medical education. 2019; 19(1):158. https://doi.org/10.1186/s12909-019-1592-0 PMid:31113435 PMCid:PMC6528316

18. Ebrahimi S, Kargar Z. Occupational stress among medical residents in educational hospitals [Internet]. Annals of occupational and environmental medicine. BioMed Central; 2018 [cited 20190ct5]. https://doi.org/10.1186/s40557-018-0262-8 PMid:30101032 PMCid:PMC6083531

19. Pulcrano M, Evans SRT, Sosin M. Quality of Life and Burnout Rates Across Surgical Specialties: A Systematic Review [Internet]. JAMA surgery. U.S. National Library of Medicine, 2016. https://doi.org/10.1001/jamasurg.2016.1647 PMid:27410167

20. Umoetok F, Van Wyk JM, Madiba TE. Does gender impact on female doctors' experiences in the training and practice of surgery? A single centre study. South African Journal of Surgery. 2017; $55(3): 8-12$. 